\title{
Research on the Scrap Auto Recovery based on the Deposits-refund System
}

\author{
Liu Hengchao \\ College of Economics, Shanghai University Shanghai, China \\ e-mail:liuhengchao86@163.com
}

\begin{abstract}
During the rapid developmental process of the automaking, the number of vehicles and the number of scrapping $n$ our nation have been substantially elevated; however, the environmental problems and traffic safety problems caused by the auto scrapping have become increasingly severer. "The insufficiency of the recovery" is a major problem faced by our nation's scrap auto recovery and utility industry. With the small passenger cars as an example, establish the system dynamic model, inspects the relation between the "depositsrefund system" and the scrap auto recovery rate. The simulation results indicates that the recovery effects of Strategy Four which is the "deposit- refund system" composed of the deposits-bonus-tax reduction are the most effective.
\end{abstract}

Keywords-scrap autos;deposits-refund system; recovery; utility;system dynamics

\section{INTRODUCTION}

As by the end of 2014, the number of vehicles owned by our nationals had reached beyond 150 million, and the number of private cars registered under the individuals' names accounted for over $90 \%$. It is specified by international standards that the scrapping rates of autos should be $6 \%$, and if we calculate the volume based on those data, our nation should scrap 9.24 million vehicles; however, the recovery volume of our national regular scrap auto recovery enterprises fell far short of the 1.9 million, with a scrapping rate of less than thirty percent, and the phenomena of illegal recovery and the illegal sales of spare parts are still prevalent, and meanwhile there are also a multitude of circumstances of illegal restructuring. All these not only cause severe damages to the environment, but also affected the road traffic safety. In order to ensure the long-term development of the industry of the scrap auto recovery, it is necessary to adopt effective measures to regulate the scrap auto recovery channels, and prevent the phenomena of illegal scrap auto recovery from occurring.

\section{RESEARCH STATUS}

In the research regarding scrap auto recovery, domestic and overseas scholars are biased on to conducting research on the factors affecting the scrap auto recovery rates or conducting exploration on the recovery mode. For example, through questionnaires, Liu Xiaoping, etc. ${ }^{[1]}$ conducted empirical analyses on the encouraging factors of the users' voluntary return of the scrap autos, and held that convenience of the recovery channels, the recovery prices of the scrap autos and the recovery enterprises are the important factors affecting the recoveries. Liu Yiwen et al. ${ }^{[2]}$ conducted research on the factors affecting the scrap auto recovery rates using the mode of questionnaire and also conducted statistical analysis on the survey results, and verified that if our nation is to have smooth implementation of the reverse logistics of scrap autos, the government needs to perfect the system of laws and regulations system, and stipulate an effective economic incentive mechanism so as to ensure the logistics channels of scrap autos reverse are unblocked. Xi Hongxun ${ }^{[3]}$ conducted analysis on the factors affecting the auto recovery rates using the Analytic hierarchy process (AHP), and held that for the elevation of our nation's scrap auto recovery and utility levels it is necessary to start from such as aspects as cracking down on the illegal dismantling market, enhancing the legal consciousness of the owners of the scrap autos, specifying the rational prices of scrap auto recoveries and implementing the system of the extension of the manufacturers' responsibilities. Such scholars as Chen Ming $^{[4]}$, based on the recovery techniques, operational links as well as the stipulations of the national relevant policies of scrap autos, and by comparing the recovery processing mechanisms of our nation and Japan, emphasized that our nation must attach great importance to the educational undertaking of environmental protection, and conduct improvements on the current status through such as the construction of the scrap disposal center, innovate the recovery. Jiro Hiratsuka, etc. ${ }^{[5]}$ conducted analysis from such three aspects as material flow, information flow and capital on the scrap auto recovery and utility system of Japan, and, through the fact of the reduction of the number of the illegally discarded scrap autos to indicate that the scrap auto recovery law was promulgated and executed in 2005 was effective. Shinichi Sakai, etc. ${ }^{[6]}$ conducted introductions on the various aspects of the scrap auto recovery and utility systems of Japan, Korea, China and the United States, such as the laws on which the recovery systems relied, the background for the promulgation of the laws, the main body of the recovery systems, the recovery objective and the characteristics of the recovery system, etc. The Paper held that, in order to enhance the development of the scrap auto recovery and utility system, it is a must strengthen international cooperation and exchanges, perfect relevant laws and regulations, and conduct proper disposals of the Automobile Shredder Residues (ASR), etc.. Some scholars made some introductions about the overseas auto recovery deposits systems, and made some proposals with pertinence 
to current status of China's auto recovery. For example, Chen Sis ${ }^{[7]}$, taking Norway, Sweden and Greece as case studies, conducted detailed analysis of the practices of the overseas environment deposit system for scrap autos, and held that the deposit system is beneficial the elevation of the auto recovery rate. It proposed that the government should establish the scrap auto environment deposit system so as to effectively solve the relevant environment problems. Cai Yong $^{[8]}$ also held that the government must make references to the experience of the developed nations, and adopt the deposit system so as to effectively elevate the scrap auto recovery rate. Some other scholars also conducted quantitative analysis on the factors affecting the scrap auto recovery rates. For example, Geng Peilin, etc. ${ }^{[9]}$ conducted analysis on the relationship between the tax refund amount and the scrap auto recovery rate through the method of mathematical modeling and derived at the relation curve of the tax refund amount and the recovery rate. Hu Shuhan ${ }^{[10]}$ established mathematical models using such methods as the nonlinear regression research and conducted simulations on the economic policies that elevate our nation's scrap auto recovery rate, and establish the numerical relation between the deposits, the recovery and utility fees, government subsidies, tax incentives and auto recovery rates, thus making a breakthrough from the circumstance in which the previous research is only confined to the qualitative analysis. In the research of the relevant scrap auto recovery modes, A.J. Spicer ${ }^{[11]}$, through the comparative analysis of the modes and means of participations in auto recoveries by different entities and proposed that when enterprises adopt a third party for conducting the recoveries they can achieve the maximization of the benefits. And such scholars as Chen Ming $^{[12]}$ proposed the recovery mode of the mutual operations of the auto manufacturers and the recovery enterprises, and conducted explanations on the functions and roles of the different entities under such a mode.

Among the literature regarding the scrap auto recovery, they most conducted the qualitative analysis, such as the factors affecting the recovery rate, the options of the recovery mode and the stipulation of the recovery system, etc., and further put forward relevant proposals. Meanwhile, there are also some scholars determined the factors affecting the scrap auto recovery rate and the relation with the recovery rate through the mathematical modeling. Although these studies got rid of the qualitative analysis, they neglected the dynamic analysis between the factor changes of the recovery rate and the changes of the recovery rate. Therefore, it is extremely necessary to adopt the system dynamics modeling so as to get rid of the previous static analyses. The dynamic analyses shall facilitate the relevant departments in their stipulating of the recovery policies.

\section{RESEARCH DESIGN}

\section{A. The "deposit-refund" system design}

As shown in Fig 1, the features of the "deposit-refund" system are that: Submission of pre-payments and later refunds. With pertinence to the scrap auto recovery, it means that from the date of the auto purchasing, an auto owners submit a certain sum of deposits annually, with these deposits becoming the capital source of the recovery fund. Finally, if the auto owners opt for the legal ways to scrap the vehicles, then all the deposits that have been prepaid by the auto owners shall be refunded in full amounts, and, based on the integrity of the vehicles, the auto owners will be granted some rewards. If auto owners opted for illegal ways to scrap their vehicles, then they will not get any benefits. The objective of the design of the system is to encourage auto owners to scrap the vehicles from the legal ways so as to reduce the occurrences of the phenomenon of the illegal recovery of scrap autos.

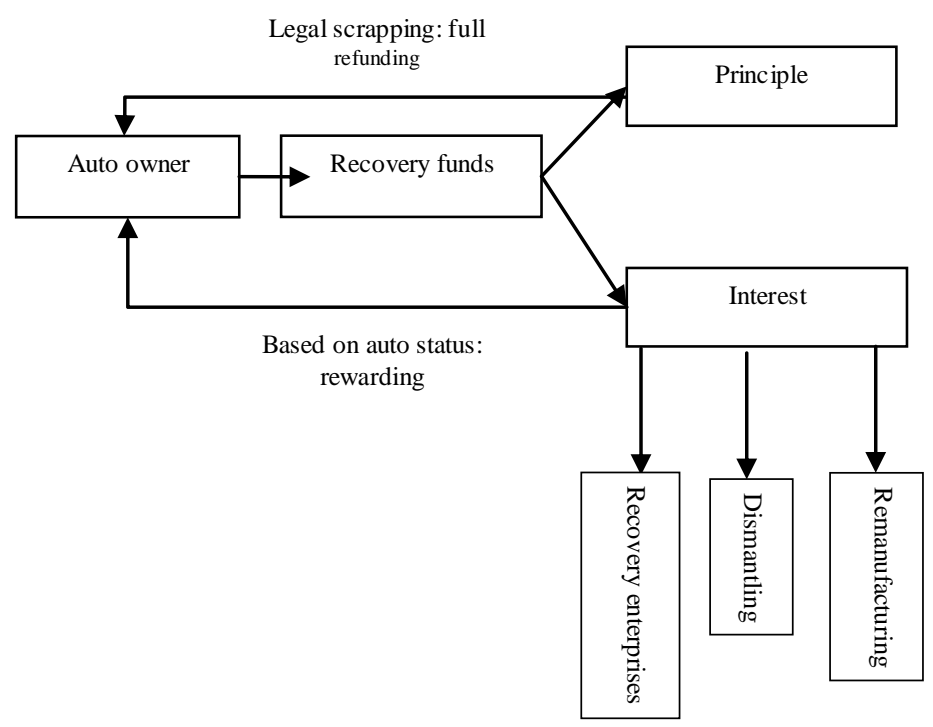

Figure 1. Scrap autos "deposit-refund" system

Meanwhile, regarding the earnings and the generated benefits from the recovery fund and, they can used for supporting the industry of scrap autos, such as the expansion and perfection of the recovery networks, the optimization of the dismantling flows of the dismantling enterprises, improvements of the dismantling and crushing techniques and the strengthening of the remanufacturing $R \& D$, etc. of remanufacturing enterprises.

\section{B. Model hypothesis and construction}

The model hypothesis are that:(1) Auto owners are typical "economic person", i.e. assume the thoughts and behaviors of the auto owners are all rational, the sole purpose of the auto owners is to maximize the material compensations. The option of the auto owners for the scrapping channels is based on which channel can bring about the maximum benefits, without any disturbances by such other factors as morality. Based on the relevant national provisions, "Five major assemblies" must be disposed of by remelting, thus leading to the waste of the economic residual values of the scrap autos, and further resulting in the enormous price differences of the legal ways and the illegal 
ways, and this is also an important reasons for the low auto scrap rate through the legal means. (2)When this Paper is conducting the research, it took the scrapping and recoveries of the small passenger cars as the case studies, and assumed each small passenger car is scrapped after a use length of 15 years. (3) No consideration is given to the time utility and values existent in the fund itself, and it is assumed that there is no economic inflation. (4) Assume the "deposit-refund" system has existed, but in the basal year, its fund sum is 0 . (5) Assume that the auto owners will buy a new vehicle after scrapping the vehicle.

Based on the above assume, establish a simulation SD model of recovery system with the recovery system as the core, as shown in Fig 2.

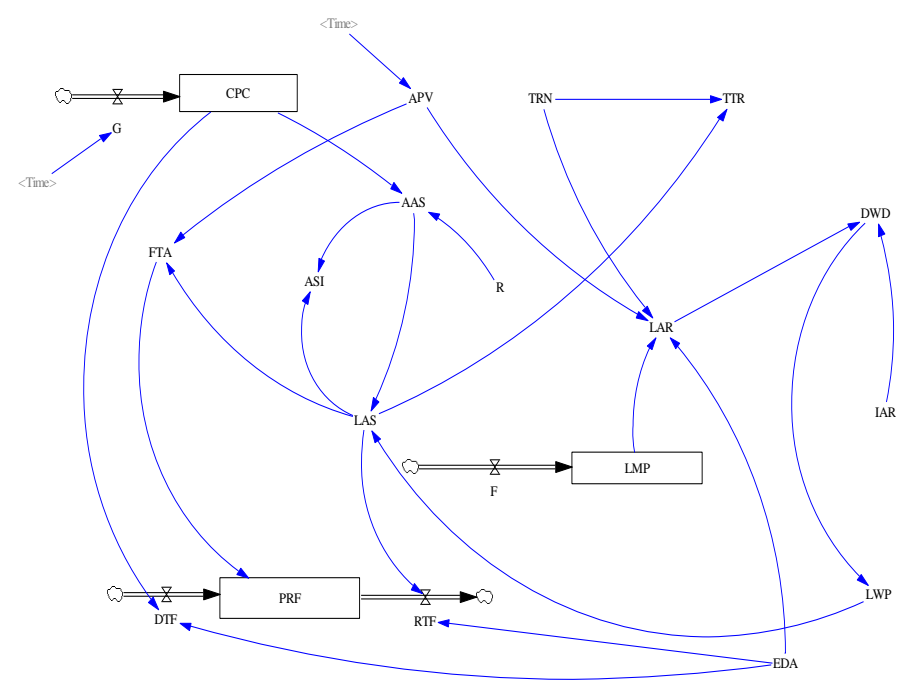

Figure 2. Scrap auto recovery system simulation SD model

\section{Model relevant data and equation}

TABLE I. NUMBER OF OUR NATION'S CIVIL SMALL PASSENGER CARS FROM 2005 2013

\begin{tabular}{|c|c|c|}
\hline Year & $\begin{array}{c}\text { Number of small passenger } \\
\text { cars (10 thousand })\end{array}$ & $\begin{array}{c}\text { Annual } \\
\text { growth rate } \\
(\%)\end{array}$ \\
\hline 2005 & 1618.349 & - \\
\hline 2006 & 2083.403 & 28.7 \\
\hline 2007 & 2646.467 & 27.0 \\
\hline 2008 & 3271.144 & 23.6 \\
\hline 2009 & 4246.897 & 29.8 \\
\hline 2010 & 5498.364 & 24.2 \\
\hline 2011 & 6827.540 & 21.6 \\
\hline 2012 & 8302.632 & 19.9 \\
\hline \hline 2013 & 9951.462 & 29.5 \\
\hline
\end{tabular}

Table 1 is number of small passenger cars of our nation between 2005 and 2013 and the annual growth rates, with the basal year of simulation set as 2005, and the simulation will end in 2025, with a time span of 20 years. Assume the scrap auto recovery fund is already in existence, but the initial fund amount is 0 , and the amounts of deposits, bonus, and the nation tax reductions, etc. are also 0 .

The model involves more than 20 variants, so in order to facilitate the description of the equation, they are listed as below:

G: Civil small passenger cars annual growth rate

CPC: Ownership of civil small passenger cars

APV: Average bonus amount per vehicle

TRN: Tax reduction amount for nation average auto purchasing

TTR: Total tax reduction for national annual carped cars

FTA: Fund total rewards

ASI: Annual scrapping amount through illegal ways

AAS: Annual average scrapping amount

$\mathrm{R}$ : Annual average scrapping rate

LAR: Legal average return

DWD: Different ways deviations

IAR: Illegal way annual returns

LAS: Legal annual scrapping

$\mathrm{F}$ : Influencing factors of the legal way recovery prices

LMP: Legal mean prices

DTF: Deposits total fund

PRF: Passenger car recovery fund

RTF: Refund of total fund

EDA: Earnings from deposits annually

LWP: Legal way scrapping proportion (1) Status variant: $\quad$ CPC $=I N T E G(C P C * G$,

Status variant: $\mathrm{PRF}=\mathrm{INTEG}(\mathrm{PRF}+\mathrm{DTF}-\mathrm{RTF}-\mathrm{FTA}$, 0)(unit: 100 thousand yuan) yuan/car)

Status variant: $\mathrm{LMP}=\mathrm{INTEG}(\mathrm{LMP} * \mathrm{~F}, 1000)$ (unit:

(2) Rate variant: G=WITHLOOKUP (Time, ([(2006,0)$(2025,1)],(2006,0.287),(2007,0.236),(2008,0.298),($ $2009,0.295),(2010,0.242),(2011,0.216),(2012,0.199$ )$,(2013,0.182),(2014,0.173),(2015,0.156),(2016,0.1$ $51),(2017,0.142),(2018,0.131),(2019,0.122),(2020,0$ $.115),(2021,0.097),(2022,0.073),(2024,0.069),(2025$ $, 0.051)))$

With the constant perfecting of the public transportation and the gradual enhancement of the national's environmental consciousness, the market of the small passenger cars will gradually tend to be saturated, and the annual growth rate of the vehicles will gradually decrease, and based on the estimates by such scholars as Zhao Hongmei ${ }^{[13]}$ and $\mathrm{Li}$ Yuxian $^{[14]}$ on the future civil small passenger cars in China, this Paper assumed that from the annual growth rate of $19 \%$ in 2013 gradually reduced to about $5 \%$ in 2025 . 
Rate variant: $\mathrm{RTF}=\mathrm{LAS} * \mathrm{EDA}^{*} 15 / 10^{4}$ (unit: 100 million yuan)

Rate variant: $\mathrm{DTF}=\mathrm{EDA} * \mathrm{CPC} / 10^{4}$ (unit: 100 million yuan)

(3) Auxiliary variant: LAS=CPC*F*LWP/100(unit: 10 thousand)

Auxiliary variant: TTR=LAS*TRN $/ 10^{4}$ (unit: 100 million yuan)

Auxiliary variant: $\mathrm{FTA}=\mathrm{APV} * \mathrm{LAS} / 10^{4}$ (unit: 100 million yuan)

Auxiliary variant:

LWP $=$ MIN $\left(99.871 / 100 * 0.969223^{\wedge}(\mathrm{DWD} / 100,1) * 100\right.$

Auxiliary variant: $\mathrm{LAR}=\mathrm{EDA} * 15+\mathrm{LMP}+\mathrm{APV}+\mathrm{TRN}$ (unit: yuan/t)

Auxiliary variant: DWD=(IAR-LAR)/1.25, (unit: yuan/t), generally, the average weight of the small passenger car is $1.25 \mathrm{t}$.

(4) Constant: $\mathrm{R}=6 \%$ (Based on the international prevailing standards)

Constant: APV=0(unit: yuan/car)

Constant: IAR=7000(unit: yuan/car)

Constant: EDA=0(unit: yuan/car)

Constant: TRN=0(unit: yuan/car)

Constant: $\mathrm{F}=0.06$, currently such a coefficient features a small effect on the recovery prices of the legal ways, therefore, the value of 0.06 was taken.

\section{Strategy design and simulation analysis}

Assume the "deposit-refund" system already in existence, with only the initial values of all the variants being 0 , and the objective of the modeling is to find a kind of low-cost and highly effective the recovery strategy, and the major reference indictors that manifest the low costs and high efficiencies include: the proportion of scrapping through legal ways, the receivable annual deposit sum per vehicle, the accumulative amount for the recovery fund of the small passenger cars, as well as the time needed by the proportion of the annual scrapping through legal ways to reach or surpass $90 \%$. The design of the recovery strategies will seek a recovery strategy through such means as adjusting the deposits, bonus and the amounts of the nation tax reduction and exemptions. The specific strategy are listed as below:

Strategy One: adjust the amounts of the deposits. Adjust the deposits to: $\mathrm{EDA}=100$ yuan.

Strategy Two: on the basis of Strategy One, adjust the average bonus amount per vehicle. Adjust the APV from 0 to 600 yuan.
Strategy Three: on the basis of Strategy Two, adjust the nation's average tax reduction amounts for auto purchasing. The TRN is adjusted from 0 to 2000 yuan.

Strategy Four: EDA is adjusted to 50 yuan, and meanwhile, APV is adjusted to 500 yuan, TRN is adjusted to 200 yuan.

Strategy Five: Adjust Influencing factors of the legal way recovery prices.F is adjusted to 0.08 , and meanwhile, EDA is adjusted 100 yuan, and APV is adjusted to 500 yuan.

The simulation results of the five kinds of strategies are shown in Fig. 3 and Fig.4. Through the analysis of the simulation results of the five kinds strategies, the following conclusions were achieved 1.As shown in Fig. 4, the five kinds of strategies are all able to effectively elevate the scrap auto recovery rate, but they presented some variations of different degrees. 2. Seen from the results of Strategy One, during the 20 years of the analogue simulation, the accumulative amount of only about $60 \%$ in the end (as shown in Fig. 4). If the recovery

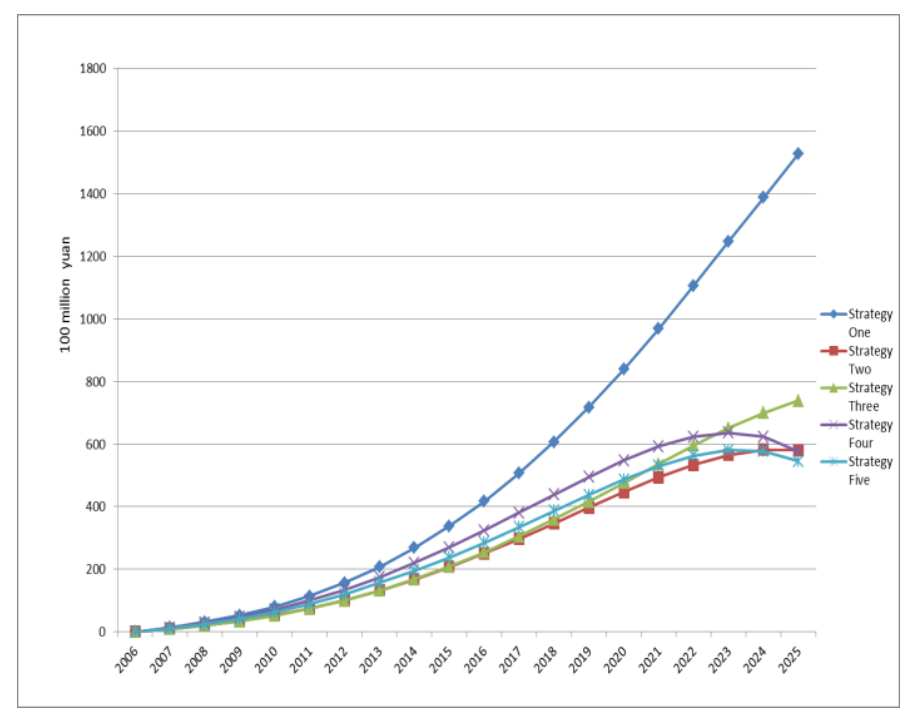

Figure 3. The recovery fund accumulation amount under different strategies (100 million yuan)

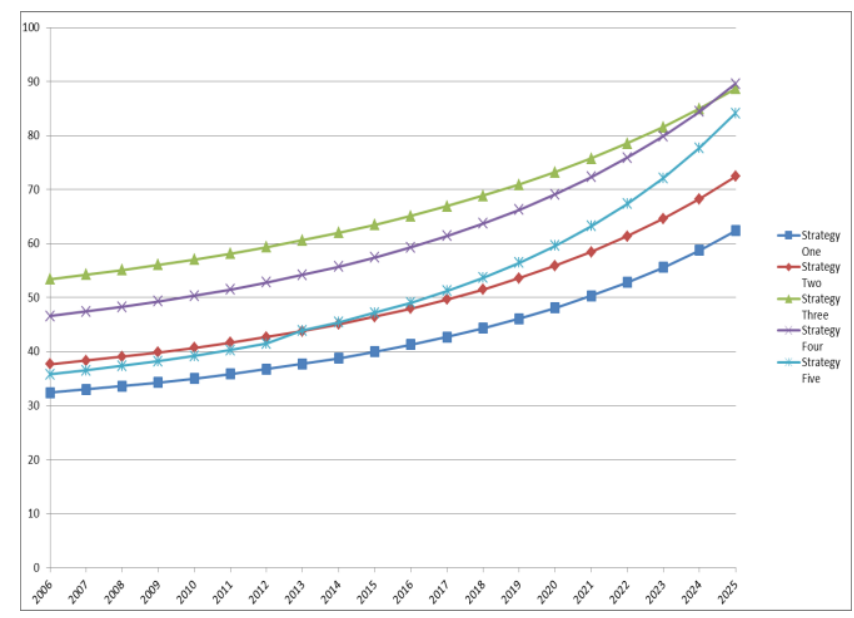

Figure 4. Scrap auto recovery rates under different strategies (\%) 
rate is to be elevated in big magnitude, the elevate deposits amount is bound to be increased, but this will cause the accumulative rate of the recovery fund to rise rapidly; from a comprehensive perspective, Strategy One is not an effective strategy, which indicates that it is impractical to solely rely on the levying of the deposits for the elevation of the recovery rate. 3.Strategy Two introduced the bonus system on the basis of Strategy One, i.e., based on the service lengths and the integrity degrees of the scrap vehicles, grant the auto owners certain rewarding. Seen from the simulation results, in contrast to Strategy One, Strategy Two can effectively prevent the great rise of the accumulative amount of the recovery fund (as shown in Fig. 3), and finally it is possible to elevate the recovery rate to about $75 \%$ (as shown in Fig. 4). Strategy Two is a relatively effective strategy; however, seen from the final results, the recovery rate is still low, and is somewhat distance from the set target value $(90 \%) .4$. The feature of Strategy Three is the introduction of the entity of the nation on the basis of Strategy Two, and assume the nation grants the auto owners who scrap the autos through the legal means some tax incentives on the purchasing of new autos and reduced a certain amount of the auto purchase tax, this not only subsidize the auto owners, but can also enhance the development of the auto-making industry. Seen from the results of the analogue simulation, although the accumulative amount of the recovery fund also rose sharply during the simulation period (as shown in Fig. 3 ), the recovery rate was greatly elevated, and it would ultimately reach $90 \%$ (as shown in Fig. 4), indicating this strategy was rather effective. 5. In contrast to Strategy One, Strategy Four adequately elevated the deposits amount, set up the adequate bonus amount, and finally introduced the national tax reduction policies. Seen from the simulation results, through the above three aspects, the accumulative amount of the fund was smoothly increased, and even experienced a tendency of decline in the alter stage (as shown in Fig. 3), with the recovery rate gradually elevated and finally was sufficient to reach $90 \%$ (as shown in Fig. 4). The results indicated that Strategy Four was effective. 6. Strategy Five introduced the price influence actors of the legal ways, and this coefficient measured the influencing extents of the recovery prices by the auto recovery system, and the major factors include the national policies, the recovery channels and the remanufacturing technological levels, etc.

Seen from the simulation results, if our nation's current scrap auto recovery system is rather perfect, then even if the deposit amount is relatively small, and there is an absence of the national tax reduction policies, Strategy Five can also achieve the results similar to those of Strategy Four (as shown in Fig. 3and Fig. 4).

\section{CONCLUSIONS}

Based on the relevant data of the our nation's civil car ownership and aided by the "deposit-refund" system, this Paper constructed the system dynamics model of the selections of the auto recovery strategies, and designed 5 kinds of the recovery strategies and conducted analogue simulations, and the research results indicated that the "deposit-refund" system could effectively elevate the scrap auto recovery rate of the legal ways, and such a system is practical and feasible. As for the balances generated by the accumulation of the recovery fund, the can be used for supporting the development of dismantling, crushing and remanufacturing enterprises, and this is beneficial for the formation of the complete industrial chains, and enhance the healthy and orderly development of the scrap auto industry.

Therefore, the nation should establish the "depositrefund" system of scrap autos, and under such a system, it is not only possible to realize the effective recovery of the scrap autos, meanwhile, it can also relieve the nation's financial pressure that is generated by the implementing of the recovery subsidies. Accordingly, regarding the auto owners who scrap their autos through the legal means, the nation should promulgate relevant tax incentives and reduction and exemption policies for auto purchases, and such measures not only can enhance the scrap auto recoveries, but is also beneficial to the development of the auto industry.

\section{REFERENCES}

[1] Liu Xiaoping, Xie Jiaping, Yin Jun. Incentive Factors of the Client's Voluntary Return of Discarded Cars [J].Contemporary Economic Management, 2007,03: 67-70.

[2] Liu Yi Wen, Zhang Yong, Yao Ying. Study of the Current Situation and Countermeasure on Chinese Waste Automobiles Recovery [J]. Value Engineering,2012,19: 308-309.

[3] Xi Hongxun. Study on Forecast of End-of-life Vehicle Recycling in China and Related Suggestions [D]. Hunan University,2012.

[4] Wang Lu, Chen Ming. Policies and perspective on end - of - life vehicles in China $[\mathrm{J}]$. Journal of Cleaner Production,2013,44(11):168-176.

[5] Hiratsuka J, Sato N, Yoshida H. Current status and future perspectives in end-of-life vehicle recycling in Japan[J]. Journal of Material Cycles and Waste Management, 2014, 16(1):21-30.

[6] Sakai S, Hideto Yoshida et al. An international comparative study of end-of-life vehicle (ELV) recycling systems[J]. Journal of Material Cycles and Waste Management, 2014, 16(1):1-20.

[7] Chen Sisi.The Practice of the Environmental Deposit System of Scrap Automobile abroad and Its Enlightenment to China [J]. Xi'an University of Architecture \& Technology (Social Science Edition), 2013,05: 23-27.

[8] Cai Yong. The Establishment of a Deposit System to Promote Chinese Scrapped Automobile Recycling [J]. China Resources Comprehensive Utilization, 2011,09: 27-28.

[9] Geng Peilin, Rong Honjun, Wang Nannan. Effect of Tax Refunds on Scrapped Automobiles Recovery $[\mathrm{J}]$. Science \& Technology for Development, 2012, s1: 28-32.

[10] Hu Shuhan. Study on Influence of Vehicle Recovery Policy on EndOf-Life Vehicle Collection Rate [D]. Hunan University, 2009.

[11] Spicer AJ. Third-party remanufacturing as a solution for extended producer responsibility[J]. Journal of Cleaner Production, 2004, 12(1):37-45

[12] Zhao Qinghua, Chen Ming. A comparison of ELV recycling system in China and Japan and Chinese strategies[J]. Resources, Conservation and Recycling, 2011, 57(11): 15-21 
[13] Zhao Hongmei. The Medium and Long Term Forecast of Chinaps Vehicle Stock per 1000 Person Based on the Gompertz Model [J]. Industrial Technological Economy, 2012,07: 7-23.
[14] Li Yuxian. The Model of the Car Ownership Forecast and Its Application Based on the S-Shaped Curve [J] Shanghai Automotive, 2014,03:27-31 